\title{
Effects of a Specialized Primary Care Facility on Preventive Service Use Among Autistic Adults: a Retrospective Claims Study
}

\author{
Brittany N. Hand, PhD, OTR/L ${ }^{1}$, , Daniel Gilmore, BS, RDN, LD? , Daniel L. Coury, MD ${ }^{1,2}$, \\ Amy R. Darragh, $P h D, O T R / L^{7}$, Susan Moffatt-Bruce, $M D, P h D, M B A^{3}$, \\ Christopher Hanks, MD', and Jennifer H. Garvin, PhD, MBA, RHIA, CPHQ, CCS, CTR \\ FAHIMA, FAHA
}

'The Ohio State University, Columbus, OH, USA; ${ }^{2}$ Nationwide Children's Hospital, Columbus, OH, USA; ${ }^{3}$ Royal College of Physicians and Surgeons in Canada, Ottawa, Canada; ${ }^{4}$ The Ohio State University Wexner Medical Center, Columbus, OH, USA.

BACKGROUND: While in some studies, the patientcentered medical home has been linked with increased receipt of preventive services among other populations, there is a paucity of literature testing the effectiveness of medical homes in serving the healthcare needs of autistic adults.

OBJECTIVE: To compare the receipt of preventive services by patients at a patient-centered medical home specifically designed for autistic adults (called the Center for Autism Services and Transition "CAST") to US national samples of autistic adults with private insurance or Medicare.

DESIGN: Retrospective study of medical billing data.

SAMPLE: The study sample included CAST patients $(N=$ 490) who were propensity score matched to Medicareenrolled autistic adults $(N=980)$ and privately insured autistic adults $(N=980)$ using demographic characteristics. The median age of subjects was 21 years old, 79\% were male, and the median duration of observation was 2.2 years.

MAIN MEASURES: The primary outcome measure was the receipt of any preventive service, as defined by the Medicare Learning Network and AAPC (formerly the American Academy of Professional Coders). Secondary outcome measures included receipt of specific preventive service types (i.e., general health and wellness services, screenings, counseling and therapies, vaccinations, and sexual/reproductive health services).

KEY RESULTS: CAST patients had significantly greater odds of receiving any preventive service than Medicareenrolled (OR $=10.3 ; 95 \% \mathrm{CI}=7.6-13.9)$ and privately insured $(\mathrm{OR}=3.1 ; 95 \% \mathrm{CI}=2.3-4.2)$ autistic adults. CAST patients were also significantly more likely to receive screenings and vaccinations than either Medicare beneficiaries (screenings $\mathrm{OR}=20.3 ; 95 \% \mathrm{CI}=14.7-28.0$; vaccinations $\mathrm{OR}=5.5 ; 95 \% \mathrm{CI}=4.3-7.0$ ) or privately insured

Prior Presentations None

Received June 10, 2020

Revised November 17, 2020

Accepted December 20, 2020

Published online January 19, 2021 beneficiaries (screenings OR $=2.0 ; 95 \% \mathrm{CI}=1.6-2.5$; vaccinations $\mathrm{OR}=3.3 ; 95 \% \mathrm{CI}=2.6-4.1$ ).

CONCLUSIONS: Autistic adults receiving care through CAST were significantly more likely to recieve preventive care services than national samples of autistic adults. Future comparative effectiveness trials are needed to rigorously assess the impact of primary care-based initiatives to improve care for autistic adults.

KEY WORDS: autism; primary care; preventive care.

J Gen Intern Med 36(6):1682-8

DOI: $10.1007 / \mathrm{s} 11606-020-06513-7$

(c) Society of General Internal Medicine 2021

\section{INTRODUCTION}

Preventive healthcare services, like immunizations, disease screenings, and behavioral counseling, are a critical component of health maintenance. However, autistic adults ${ }^{1}$ face barriers to accessing and using such services at the patient, provider, and systems levels. ${ }^{1-3}$ Patientlevel factors that may be barriers to care include challenges with communication, sensory processing, and emotional regulation. For example, challenges with sensory processing can make it more difficult for patients to describe symptoms of health conditions they are experiencing (e.g., differentiating shooting pain from a dull ache). ${ }^{1}$ Provider-level characteristics, such as a lack of knowledge about autism or unwillingness to provide accommodations to meet sensory and communication needs, can also reduce the accessibility of healthcare for autistic adults. ${ }^{1}$ Finally, system-level factors, such as characteristics of the facilities (e.g., loud, crowded, bright lighting) and unavailability of formal or informal supports to help autistic adults navigate the complexities of the healthcare system, can serve as barriers to care. ${ }^{1}$ As a result of these barriers, autistic adults receive fewer preventive services than the general population. ${ }^{4,5}$

This disparity in receipt of preventive services is concerning because autistic adults are at greater risk for physical and 
mental health conditions that can be identified with routine screening. ${ }^{6-8}$ Additionally, decreased receipt of preventive services has implications for the healthcare system and patient health outcomes, potentially contributing to increased emergency department use, higher healthcare costs, and underaddressed chronic health conditions among autistic adults. ${ }^{9-}$

${ }^{12}$ As a result, there is an urgent need to develop and test systems of healthcare delivery that are better equipped to meet the needs of autistic adults ${ }^{13}$ in order to promote receipt of important preventive services and improve autistic adults' health outcomes.

The patient-centered medical home (PCMH) is one model of healthcare delivery in the US healthcare system that may be effective at increasing autistic adults' receipt of preventive care services. The PCMH is characterized by a primary care physician who coordinates patient care to promote timely delivery of needed health services. ${ }^{14-16}$ Specifically, the PCMH may increase the receipt of preventive services through a "comprehensive approach to ongoing prevention, routine medical management, and care coordination [...] while working in collaboration with specialty care and other providers." For example, the PCMH provides preventive visits, treatment for physical and mental health conditions, management of chronic conditions, and treatment for acute conditions. ${ }^{14}$ There is mixed evidence of the effectiveness of the PCMH among the general population and individuals with a variety of clinical conditions. ${ }^{17}$ Some studies have found that the PCMH is associated with increased receipt of preventive services, ${ }^{18}$ greater access to care, ${ }^{19}$ and fewer emergency department visits, ${ }^{20}$ while other studies have not. ${ }^{21-23}$ However, there is a lack of evidence testing the effectiveness of the PCMH in meeting the healthcare needs of autistic adults. ${ }^{24} \mathrm{We}$ will address this gap in the literature in the present study; our objective was to compare preventive service utilization among patients at a specialized PCMH designed for autistic adults to matched national samples of privately and publicly insured autistic adults.

\section{METHODS}

\section{Study Design and Setting}

We conducted a retrospective cross-sectional study to compare the receipt of preventive services among patients who receive care through the Center for Autism Services and Transition (CAST) to national samples of autistic adults with private insurance or public (Medicare) insurance. CAST is a PCMH that was designed in partnership with autistic adults and their caregivers (e.g., parents, legal guardians, adult siblings) to minimize barriers to care. ${ }^{2}$ Prior cross-sectional observational studies have shown that CAST patients have significantly better continuity of care ${ }^{25}$ and higher satisfaction with care ${ }^{26}$ than national samples of autistic adults. Supplemental Material 1 provides additional information about CAST.

\section{Data Sources}

We used data from our institutional Information Warehouse (IW), IBM MarketScan, and Medicare Standard Analytic Files (SAF). The CAST patient records, obtained from our institutional IW, represented outpatient visits that occurred between November 1, 2014, and October 31, 2019, at any location or with any provider within our system. We obtained de-identified, individual-level, outpatient health records from a national sample of autistic adults with private insurance from the MarketScan Commercial Claims and Encounters Databases for the years 2012-2016. Finally, we obtained a national sample of autistic adult Medicare beneficiaries from Medicare SAF for the years 2013-2017. Supplemental Material 1 contains additional information about data sources.

\section{Sample Identification}

Individuals were included this analysis if they were aged 1860 years and had at least one ${ }^{27}$ medical encounter with an autism diagnosis, as defined by International Classification of Diseases, $9^{\text {th }}$ edition (ICD-9) or ICD-10 codes for autistic disorder (299.0x, F84,0), atypical autism (F84.1), Asperger's syndrome (299.8x, F84.5), or pervasive developmental disorder unspecified (299.9x, F84.9). CAST patients were included if they received care through CAST for at least 6 months to ensure adequate time for measuring outcomes. We excluded individuals from the MarketScan and Medicare databases who live in the same state as CAST to reduce the possibility that CAST patient records were captured with these data sources.

Propensity Score Matching. We used propensity score matching to identify subsets of eligible beneficiaries with private insurance and Medicare who were similar to CAST patients in terms of baseline characteristics. We used seven covariates for propensity score matching: age in years at first observed visit, sex, rural residence, intellectual disability, duration of observation, number of outpatient visits, and Charlson Comorbidity Index. ${ }^{28}$ Supplemental Material 1 provides additional information about propensity score matching, including how variables in the model were defined.

\section{Variable Definitions}

Demographic variables were extracted from the first recorded date of service. The primary independent variable was cohort membership. The dependent variable was the presence or absence of healthcare records for receipt of preventive care services. For our dependent variables, we used the Medicare Learning Network ${ }^{29}$ and $\mathrm{AAPC}^{30}$ (formerly the "American Academy of Professional Coders") definitions to identify medical encounters for 32 types of preventive services based on diagnosis and procedural codes. Our primary dependent variable was the receipt of any preventive service. As secondary dependent variables, we grouped the 32 preventive 
services into five sub-categories: (1) general health and wellness; (2) screenings; (3) counseling and therapies; (4) vaccinations; and (5) sexual/reproductive health. Figure 1 lists each preventive service and designates sub-category assignments.

\section{Statistical Analysis}

Descriptive statistics were used to summarize the demographic characteristics of the sample. Categorical variables are reported as frequencies and percentages, while continuous variables are reported as medians and interquartile ranges. We used logistic regression to compare CAST patients to national samples of autistic adults with Medicare or private health insurance on the odds of receiving any preventive service, as well as the odds of receiving services in each preventive service category (Fig. 1). As a post hoc sensitivity analysis to determine the effect of CAST payor mix on our findings, we (1) compared the subset of CAST patients who were insured by Medicare to their Medicare-enrolled propensity scorematched peers and (2) compared the subset of CAST patients who were privately insured to their privately insured propensity score-matched peers. All regression models controlled for age at first observed visit, sex, intellectual disability, rural residence, Charlson Comorbidity Index, and duration (weeks) of observation.

\section{Ethical Approval}

The Institutional Review Board (IRB) reviewed this study and determined it to be IRB-exempt (Protocol Number: 2019E0283).

\section{RESULTS}

The final matched sample consisted of 490 CAST patients, 980 Medicare beneficiaries, and 980 privately insured beneficiaries. Most CAST patients $(63.3 \%)$ were privately insured $(N=310)$; approximately $24.9 \%$ were insured by Medicaid $(N=122), 11.0 \%$ were insured by Medicare $(N=$ $54)$, and $<1 \%$ were uninsured $(N=4)$. Demographic information about each cohort is shown in Table 1. Most autistic adults included in this analysis were male, did not have an intellectual disability, and lived in non-rural areas. The cohorts were similar with regard to median age, Charlson comorbidity indices, and weeks observed. All CAST patients were residents of the state of Ohio. With regard to the national samples, the Southern US was the most common region of residence for those with Medicare (27.4\%) or private insurance (37.3\%).

Table 2 provides descriptive information about preventive services for each cohort and results of the multivariable logistic regression models. CAST patients had over 10 times greater odds than Medicare beneficiaries $(\mathrm{OR}=10.3 ; 95 \% \mathrm{CI}=$ 7.6-13.9) and 3 times greater odds than privately insured beneficiaries $(\mathrm{OR}=3.1 ; 95 \% \mathrm{CI}=2.3-4.2)$ of receiving any preventive service. Additionally, CAST patients were significantly more likely to receive screenings and vaccinations than either Medicare or privately insured beneficiaries. CAST patients were $70 \%$ less likely than Medicare beneficiaries (OR = $0.3,95 \% \mathrm{CI}=0.2-0.5$ ) to receive counseling and therapy preventive services but did not differ from privately insured beneficiaries. No differences were observed between CAST patients and the other two cohorts on the odds of receiving sexual and reproductive health services.

Results of the post hoc sensitivity analysis to determine the potential influence of CAST payor mix on our findings are shown in Table 3. These stratified analyses revealed that CAST patients were significantly more likely than similarly insured national samples of autistic adults to receive any preventive service, screenings, and vaccinations. Additionally, CAST patients who were insured by Medicare were significantly more likely than a national sample of autistic Medicare

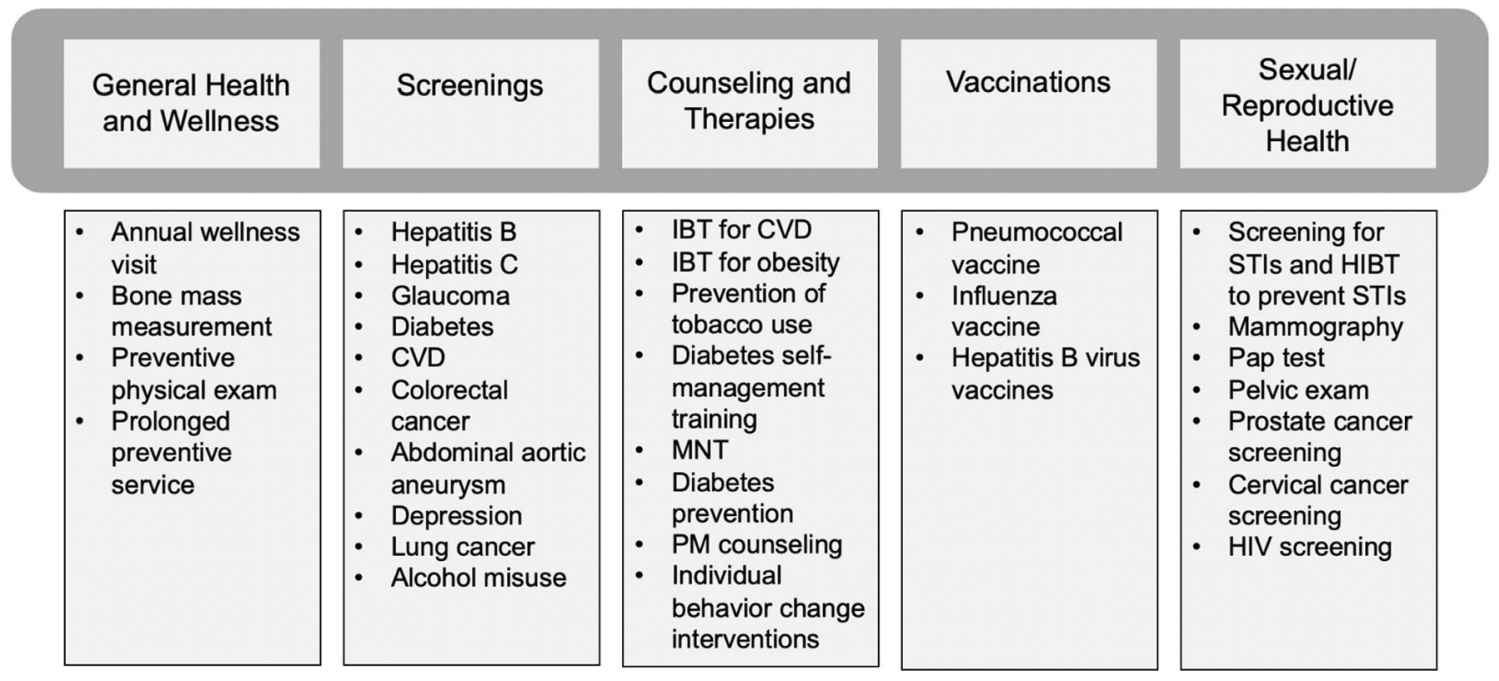

Figure 1 Classification of preventive services into five categories. CVD, cardiovascular disease; IBT, intensive behavioral therapy; MNT, medical nutrition therapy; PM, preventive medicine; STI, sexually transmitted infection; HIBT, high intensity behavioral therapy; HIV, human immunodeficiency virus. 
Table 1 Sample Characteristics

\begin{tabular}{|c|c|c|c|}
\hline Variable & $\begin{array}{l}\text { CAST } \\
N=490\end{array}$ & $\begin{array}{l}\text { Medicare } \\
N=980\end{array}$ & $\begin{array}{l}\text { Privately } \\
\text { insured } \\
N=980\end{array}$ \\
\hline Male, $N(\%)$ & $388(79.2)$ & $791(80.7)$ & $760(77.6)$ \\
\hline $\begin{array}{l}\text { Intellectual disability, } N \\
(\%)\end{array}$ & $83(16.9)$ & 185 (18.9) & $165(16.8)$ \\
\hline \multicolumn{4}{|l|}{ Race/ethnicity, $N(\%)$} \\
\hline White non-Hispanic & $384(78.4)$ & $691(70.5)$ & \\
\hline Black non-Hispanic & $60(12.2)$ & $155(15.8)$ & \\
\hline Hispanic & $12(2.4)$ & $48(4.9)$ & \\
\hline Other, or unknown & $34(6.9)$ & $86(8.8)$ & $980(100)^{\mathrm{a}}$ \\
\hline \multicolumn{4}{|l|}{ US region, $N(\%)$} \\
\hline \multicolumn{4}{|l|}{ Northeast } \\
\hline New England & & $92(9.4)$ & $38(3.9)$ \\
\hline Middle Atlantic & & $171(17.5)$ & $211(21.7)$ \\
\hline Midwest & $490(100)$ & & \\
\hline East North Central & $490(100)$ & $130(13.3)$ & $100(10.3)$ \\
\hline West North Central & & 109 (11.1) & $48(4.9)$ \\
\hline \multicolumn{4}{|l|}{ South } \\
\hline South Atlantic & & $162(16.6)$ & $203(20.8)$ \\
\hline East South Central & & $38(3.9)$ & $43(4.4)$ \\
\hline West South Central & & 77 (7.9) & $118(12.1)$ \\
\hline \multicolumn{4}{|l|}{ West } \\
\hline Mountain & & $54(5.5)$ & $86(8.8)$ \\
\hline Pacific & & $145(14.8)$ & $127(13)$ \\
\hline Rural, $N(\%)$ & $28(5.7)$ & $68(6.9)$ & $46(4.7)$ \\
\hline $\begin{array}{l}\text { Age in years, median } \\
\text { (IQR) }\end{array}$ & $21(20,25)$ & $21(20,25)$ & $21(19,24)$ \\
\hline $\begin{array}{l}\text { Charlson Comorbidity } \\
\text { Index, median (IQR) }\end{array}$ & $0(0,0)$ & $0(0,0)$ & $0(0,0)$ \\
\hline $\begin{array}{l}\text { Weeks Observed, median } \\
\text { (IQR) }\end{array}$ & $\begin{array}{l}118(55, \\
190)\end{array}$ & $\begin{array}{l}108(48, \\
183)\end{array}$ & $\begin{array}{l}113(44, \\
216)\end{array}$ \\
\hline
\end{tabular}

CAST, Center for Autism Services and Transition; US, United States; $I Q R$, interquartile range; N/A, not applicable, test not performed as variable was not included in propensity score matching

${ }^{a}$ Unknown as race and ethnicity data are not provided in MarketScan databases

${ }^{b}$ The Charlson Comorbidity Index (CCI) rates identifies the presence of 22 health conditions including heart disease, cancer, and acquired immunodeficiency syndrome. ${ }^{28}$ Each condition is assigned a score of 1 , 2, 3, or 6 depending on the risk of mortality. If an individual has none of these conditions, they are assigned a CCI of 0. In this study, at least $75 \%$ of individuals included in each cohort had a CCI of 0

beneficiaries to receive sexual and reproductive health services $(\mathrm{OR}=5.3,95 \% \mathrm{CI}=2.0-13.9)$ and general health and wellness services (33\% of Medicare-enrolled CAST patients vs $0 \%$ of Medicare-enrolled national sample). No differences were observed between CAST patients and similarly insured national samples of autistic adults on the odds of receiving counseling and therapy services. Additionally, privately insured CAST patients did not significantly differ from a national sample of privately insured autistic adults in the odds of receiving general health and wellness screenings or sexual and reproductive health services.

\section{DISCUSSION}

Improved health outcomes, such as reduced mortality, ${ }^{31}$ morbidity, and hospitalizations, ${ }^{32}$ are associated with the receipt of routine preventive healthcare services. However, autistic adults receive fewer preventive healthcare services than the general population. ${ }^{4,5}$ As the population of autistic adults grows ${ }^{13}$ there is an urgent need to address this disparity in the receipt of preventive services by developing and testing evidence-based models of healthcare delivery that may better meet this population's needs. Our study addresses this priority research area by determining the extent to which a patientcentered medical home (PCMH) designed for autistic adults is associated with increased receipt of preventive services.

Our results revealed that patients who receive care through a specialized PCMH for autistic adults, called CAST, were significantly more likely than national samples of autistic adult peers to receive any preventive care service, screenings, and vaccinations. Additionally, while the receipt of sexual and reproductive health among all cohorts was low, the odds of CAST patients receiving sexual and reproductive health preventive services were significantly greater than those of Medicare-enrolled autistic adults, and similar to privately insured autistic adults. These findings are encouraging, indicating that patient-centered approaches for autistic adults may be effective for promoting receipt of preventive services, which are especially important for autistic adults as they are at greater risk for many conditions that can be prevented, identified, and/ or managed with routine preventive care like hypertension, heart disease, and diabetes. ${ }^{8,33}$ Increased receipt of preventive services among our CAST sample, therefore, may support prevention, early identification, and treatment of co-

Table 2 Preventive services received by autistic adults in the USA

\begin{tabular}{|c|c|c|c|c|c|}
\hline \multirow[b]{2}{*}{ Preventive service } & \multicolumn{3}{|c|}{$\begin{array}{l}\text { Number of autistic adults who received preventive } \\
\text { services, } N(\%)\end{array}$} & \multicolumn{2}{|c|}{$\begin{array}{l}\text { Odds of CAST patients having each } \\
\text { preventive service type, OR }(95 \% \mathrm{CI}) *\end{array}$} \\
\hline & CAST $(N=490)$ & $\begin{array}{l}\text { Medicare } \\
(N=980)\end{array}$ & $\begin{array}{l}\text { Privately insured } \\
(N=980)\end{array}$ & Medicare (ref) & Privately insured (ref) \\
\hline $\begin{array}{l}\text { Any preventive service } \\
\text { General health and wellness } \\
\text { Screenings } \\
\text { Counseling and therapies } \\
\text { Vaccinations } \\
\text { Sexual/reproductive health }\end{array}$ & $\begin{array}{l}429(87.6) \\
238(48.6) \\
268(54.7) \\
36(7.3) \\
284(58.0) \\
66(13.5)\end{array}$ & $\begin{array}{l}412(42.0) \\
12(1.2) \\
67(6.8) \\
176(18.0) \\
200(20.4) \\
93(9.5)\end{array}$ & $\begin{array}{l}687(70.1) \\
499(50.9) \\
390(39.8) \\
63(6.4) \\
304(31.0) \\
133(13.6)\end{array}$ & $\begin{array}{l}10.3(7.6-13.9) \\
83.4(45.7-152.3) \\
20.3(14.7-28.0) \\
0.3(0.2-0.5) \\
5.5(4.3-7.0) \\
1.4(1.0-2.1)\end{array}$ & $\begin{array}{l}3.1(2.3-4.2) \\
0.9(0.7-1.1) \\
2.0(1.6-2.5) \\
1.2(0.8-1.8) \\
3.3(2.6-4.1) \\
1.1(0.8-1.5)\end{array}$ \\
\hline
\end{tabular}

*Odds ratios (OR) and 95\% confidence intervals (CI) depict the odds of patients at the Center for Autism Services and Transition (CAST) having the preventive service, relative to Medicare or privately insured patients as the reference (ref) group. Results were obtained through logistic regression models controlling for sex, age, Charlson Comorbidity index, rural residence, intellectual disability, and duration (weeks) of observation 
Table 3 Post Hoc Analysis of Preventive Care Use by CAST Patient Insurance Type

\begin{tabular}{|c|c|c|c|c|c|c|}
\hline \multirow[t]{2}{*}{ Preventive service } & \multicolumn{3}{|c|}{ Medicare beneficiaries } & \multicolumn{3}{|c|}{ Privately insured beneficiaries } \\
\hline & $\begin{array}{l}\text { CAST } \\
(N=54)\end{array}$ & $\begin{array}{l}\text { Matched National } \\
\text { Sample }(N=108)\end{array}$ & $\begin{array}{l}\text { OR* } \\
(95 \% \mathrm{CI})\end{array}$ & $\begin{array}{l}\text { CAST } \\
(N=310)\end{array}$ & $\begin{array}{l}\text { Matched National } \\
\text { Sample }(N=620)\end{array}$ & $\begin{array}{l}\text { OR* } \\
(95 \% \mathrm{CI})\end{array}$ \\
\hline Any preventive service, $N(\%)$ & $51(94.4)$ & $50(46.3)$ & $23.0(6.5-80.9)$ & $271(87.4)$ & $445(71.8)$ & $3.0(2.0-4.5)$ \\
\hline General health and wellness & $18(33.3)$ & $0(0.0)$ & $\mathrm{NA}^{\dagger} \mathrm{C}$ & $156(50.3)$ & $331(53.4)$ & $0.9(0.7-1.2)$ \\
\hline Screenings & $48(88.9)$ & $10(9.3)$ & $180(41.9-773.9)$ & $151(48.7)$ & $243(39.2)$ & $1.7(1.3-2.3)$ \\
\hline Counseling and therapies & $8(14.8)$ & $25(23.1)$ & $0.5(0.2-1.3)$ & $23(7.4)$ & $40(6.5)$ & $1.1(0.7-2.0)$ \\
\hline Vaccinations & $37(68.5)$ & $20(18.5)$ & $16.0(6.4-39.9)$ & $184(59.4)$ & $189(30.5)$ & $3.9(2.9-5.3)$ \\
\hline Sexual/reproductive health & $16(29.6)$ & $11(10.2)$ & $5.3(2.0-13.9)$ & $38(12.3)$ & $90(14.5)$ & $0.9(0.6-1.5)$ \\
\hline
\end{tabular}

* Odds ratios (OR) and 95\% confidence intervals (CI) depict the odds of patients at the Center for Autism Services and Transition (CAST) having the preventive service, relative to Medicare or privately insured patients. Results were obtained through logistic regression models controlling for sex, age, Charlson Comorbidity index, rural residence, intellectual disability, and duration (weeks) of observation

${ }^{\dagger}$ Logistic regression could not be performed as no Medicare beneficiaries included in this sensitivity analysis received this type of preventive service

occurring conditions, thereby leading to better long-term health outcomes.

CAST patients were equally as likely as a national sample of privately insured autistic adults and significantly more likely than a national sample of Medicare-enrolled autistic adults to receive general health and wellness services. ${ }^{8}$ This finding may largely be due to differences between Medicare and private insurance coverage for the preventive services in this category. Specifically, while most private insurers cover periodic preventive physical examinations, ${ }^{34,35}$ Medicare only covers one preventive physical exam per beneficiary, which must take place within 12 months of initial Medicare Part B enrollment. ${ }^{36}$ However, Medicare does cover annual wellness exams, which do not include a physical examination but instead focus on developing a personalized prevention plan for the beneficiary's future medical issues based on their health and risk factors. ${ }^{37}$ While the annual wellness exam was introduced as a Medicare-covered preventive service in 2011, as of the year 2015, less than half of the practices with eligible Medicare patients offered annual wellness visits. ${ }^{38}$ This contributed to infrequent receipt of this preventive service, with less than $20 \%$ of eligible Medicare beneficiaries receiving an annual wellness visit. ${ }^{38}$

While CAST patients and privately insured autistic adults had similar odds of receiving counseling and therapy, CAST patients were significantly less likely than autistic adults insured by Medicare to receive this preventive service type. Our sensitivity analysis revealed, however, that when CAST patients were stratified by insurance type, this difference was no longer significant. As such, the observed difference in our primary analysis was likely due to variability in insurance coverage for these types of services, rather than model of care delivery. For example, Medicare Part B covers medical nutrition therapy (MNT) for patients with diabetes, ${ }^{39}$ intensive behavioral therapy (IBT) for cardiovascular disease, and IBT for obesity at no cost to the beneficiary. ${ }^{40,41}$ However, the private health insurance market is highly variable in terms of coverage of services and associated costs to beneficiaries, which may result in financial barriers to these types of services. Indeed, for three of the largest private health insurers in the USA, services like MNT and IBT may be associated with a copay, or only be covered under certain circumstances, such as when bundled as part of a medical examination. ${ }^{34,35,42} \mathrm{Al}-$ though PCMH practices are specifically designed to deliver comprehensive care, ${ }^{13}$ lack of insurance coverage for certain services, like counseling and therapy preventive services, may preclude delivery of those services.

There are a number of characteristics of CAST that may be responsible for the increased receipt of preventive care services, screenings, and vaccinations. In part, these findings may be due to characteristics that are inherent to the PCMH, such as coordination of care and patient-centeredness. ${ }^{14}$ CAST, however, differs from the standard PCMH in its customization for autistic adults and it may, in fact, be these customizations that contribute to the observed increase in receipt of preventive care. For example, CAST has designated primary care physicians with extensive experience working with autistic adults and established processes in place to anticipate accommodations to care that autistic adults may need. ${ }^{2}$ As such, in future work, it will be important to identify the most significant drivers of CAST patient outcomes in preparation for replication in other communities. It will also be important in future work to conduct local needs assessments to evaluate the feasibility of developing similar programs in other contexts (e.g., rural areas, non-academic medical centers).

When interpreting our findings, it is important to note that there are some limitations with the comparison groups used in this study. The billing records for CAST patients, privately insured autistic adults, and Medicare-enrolled autistic adults were from different time periods, with the CAST records being the most recent. The national sample of Medicare beneficiaries was comprised of a greater number of individuals in minority groups, which may have influenced our results, as minority groups experience well-documented healthcare disparities. ${ }^{43}$ Additionally, we did not have access to race/ ethnicity data for our privately insured sample, and therefore could not control for these factors in the analysis. It is also possible that the population comparison groups differed in their access to care as a result of being from different geographic regions than CAST patients. ${ }^{44}$ The population 
comparison groups did not include Medicaid beneficiaries; comparing preventive care utilization among CAST patients to a comparison sample of autistic adults covered by Medicaid will be important for future work.

In addition to comparison group limitations, there are also limitations associated with using medical billing data for research. We identified autism and intellectual disability using only medical billing records without independent verification by our research team. Medical billing data do not contain many variables associated with health status and health outcomes, such as socioeconomic status ${ }^{45}$ and social support. ${ }^{46}$ Furthermore, medical visits made by CAST patients that were outside of our institution's healthcare system were not included in the data that we received from our institution's Information Warehouse. The Medicare and MarketScan databases only include claims that were submitted to insurance; services received by autistic adults but were not billed to insurance would not be included. While we minimized the likelihood that autistic adults in the national samples received care through CAST by excluding those from the state in which CAST is located, we cannot know whether they received care through another PCMH. Considering alternate sources of data that would allow for us to control for healthcare delivery model will be an important step for future work. Additionally, receipt of preventive care is not the only factor that indicates the effectiveness of a PCMH like CAST. In this study, we did not examine other important components of effectiveness such as quality of care and comprehensiveness. Outcomes such as these should be examined in future studies for a comprehensive evaluation of the effectiveness of a PCMH for autistic adults.

\section{CONCLUSION}

We compared receipt of preventive services among autistic adult patients at CAST, a PCMH specifically designed for autistic adults, relative to US national samples of autistic adults with public or private insurance. CAST patients were significantly more likely to receive any preventive care service, screenings, and vaccinations than national samples of autistic adult peers. Our findings support a specialized PCMH consisting of healthcare providers who are knowledgeable about autism as a promising solution to improve healthcare delivery for this population; however, randomized trials or comparative effectiveness studies would be needed to confirm this.

Supplementary Information The online version contains supplementary material available at https://doi.org/10.1007/s11606-020-06513-7.

Corresponding Author: Brittany N. Hand, PhD, OTR/L; The Ohio State University, Columbus, OH, USA (e-mail: hand.58@osu.edu).
Funding The project described was supported by Award Number Grant 5KL2TRO02734-02 from the National Center for Advancing Translational Sciences and Autism Speaks grant number 11761.

\section{Compliance with Ethical Standards:}

Conflict of Interest: The authors report grants from Autism Speaks and from the National Center for Advancing Translational Sciences during the conduct of the study. Christopher Hanks is the founder and medical director of CAST. CAST has received funding from the White Castle Foundation and Bill and Marci Ingram for program costs.

Disclaimer: The content is solely the responsibility of the authors and does not necessarily represent the official views of the National Center for Advancing Translational Sciences, the National Institutes of Health, or Autism Speaks.

\section{REFERENCES}

1. Nicolaidis C, Raymaker DM, Ashkenazy E, et al. "Respect the way I need to communicate with you": Healthcare experiences of adults on the autism spectrum. Autism. 2015;19(7):824-831. https://doi.org/10. $1177 / 1362361315576221$.

2. Saqr Y, Braun E, Porter K, Barnette D, Hanks C. Addressing medical needs of adolescents and adults with autism spectrum disorders in a primary care setting. Autism. 2018;22(1):51-61. https://doi.org/10. $1177 / 1362361317709970$.

3. Mason D, Ingham B, Urbanowicz A, et al. A systematic review of what barriers and facilitators prevent and enable physical healthcare services access for autistic adults. J Autism Dev Disord. 2019;49(8):3387-3400. https://doi.org/10.1007/s10803-019-04049-2.

4. Nicolaidis C, Raymaker D, McDonald K, et al. Comparison of healthcare experiences in autistic and non-autistic adults: a crosssectional online survey facilitated by an Academic-Community Partnership. J Gen Intern Med. 2013;28(6):761-769. https://doi.org/10.1007/ s11606-012-2262-7.

5. Zerbo O, Gian Y, Ray T, et al. Healthcare service utilization and cost among adults with autism spectrum disorders in a U.S. Integrated Healthcare system. Autism Adulthood. 2018. https://doi.org/10.1089/ aut.2018.0004.

6. Benachenhou S, Etcheverry A, Galarneau L, Dubé J, Çaku A. Implication of hypocholesterolemia in autism spectrum disorder and its associated comorbidities: a retrospective case-control study. Autism Res. 2019;12(12):1860-1869. https://doi.org/10.1002/aur.2183.

7. Chen $\mathbf{M}-\mathbf{H}, \mathbf{L a n} \mathbf{W}-\mathbf{H}, \mathbf{H s u} \mathbf{J}-\mathbf{W}$, et al. Risk of developing type 2 diabetes in adolescents and young adults with autism spectrum disorder: a nationwide longitudinal study. Diabetes Care. 2016;39(5):788-793. https://doi.org/10.2337/dc15-1807.

8. Croen LA, Zerbo O, Gian Y, et al. The health status of adults on the autism spectrum. Autism. 2015;19(7):814-823. https://doi.org/10. $1177 / 1362361315577517$.

9. Shields MC, Akobirshoev I, Dembo RS, Mitra M. Self-injurious behavior among adults with ASD: hospitalizations, length of stay, and costs of resources to deliver care. PS. 2019;70(6):457-464. https://doi. org/10.1176/appi.ps.201800318.

10. Turcotte P, Mathew M, Shea LL, Brusilovskiy E, Nonnemacher SL. Service needs across the lifespan for individuals with autism. J Autism Dev Dis. 2016;46(7):2480-2489. https://doi.org/10.1007/s10803-0162787-4.

11. Vohra R, Madhavan S, Sambamoorthi U. emergency department use among adults with Autism Spectrum Disorders (ASD). J Autism Dev Disord. 2016;46(4):1441-1454. https://doi.org/10.1007/s10803-0152692-2

12. Hand BN, Boan AD, Bradley CC, Charles JM, Carpenter LA. Emergency department utilization and monetary charges in adolescents with autism spectrum disorder, intellectual disability, and a population comparison group. Autism Res. 2019;12(7):1129-1138. https://doi.org/ 10.1002/aur.2124.

13. Interagency Autism Coordinating Committee (IACC). 2016-2017 Interagency Autism Coordinating Committee Strategic Plan For Autism Spectrum Disorder. Published online October 2017. https://iacc.hhs. gov/publications/strategic-plan/2017/. Accessed March 2, 2020. 
14. Waisman Center U of W-M. Medical home services for autism spectrum disorders. Published online 2008. https://www2.waisman.wisc.edu/ cedd/guidelines/pdf/Autism_Flip.pdf. Accessed December 18, 2019.

15. Shahidullah JD, Azad G, Mezher KR, McClain MB, McIntyre LL. Linking the medical and educational home to support children with autism spectrum disorder: practice recommendations. Clin Pediatr (Phila). 2018;57(13): 1496-1505. https://doi.org/10.1177/ 0009922818774344.

16. Raymaker DM, MCDonald KE, Ashkenazy E, et al. Barriers to healthcare: Instrument development and comparison between autistic adults and adults with and without other disabilities. Autism. 2017;21(8):972-984. https://doi.org/10.1177/1362361316661261.

17. Veet CA, Radomski TR, D'Avella C, et al. Impact of healthcare delivery system type on clinical, utilization, and cost outcomes of patient-centered medical homes: a systematic review. J Gen Intern Med. 2020;35(4):12761284. https://doi.org/10.1007/s11606-019-05594-3.

18. Kicinger IM, Cuellar A, Helmchen LA, et al. Quality of care and preventive screening use in the carefirst patient-centered medical home program. J Healthc Qual. 2019;41(6):339-349. https://doi.org/10. 1097/JHQ.0000000000000169.

19. Timbie JW, Hussey PS, Setodji CM, et al. Association between patientcentered medical home capabilities and outcomes for medicare beneficiaries seeking care from federally qualified health centers. J Gen Intern Med. 2017;32(9):997-1004. https://doi.org/10.1007/s11606-017-4078y.

20. Chaiyachati KH, Gordon $\mathbf{K}$, Long $\mathbf{T}$, et al. Continuity in a VA patientcentered medical home reduces emergency department visits. PLOS ONE. 2014;9(5):e96356. https://doi.org/10.1371/journal.pone.0096356.

21. Baughman AW, Brawarsky $\mathbf{P}$, Onega $\mathbf{T}$, et al. Medical home transformation and breast cancer screening. Am J Manag Care. 2016;22(11):e382-e388.

22. Romaire MA, Keyes V, Parish WJ, Kim K. Impact of medical homes on expenditures and utilization for beneficiaries with behavioral health conditions. PS. 2018;69(8):871-878. https://doi.org/10.1176/appi.ps. 201700433.

23. Kern LM, Edwards A, Kaushal R. The patient-centered medical home and associations with health care quality and utilization: a 5-year cohort study. Ann Intern Med. 2016;164(6):395-405. https://doi.org/10.7326/ M14-2633.

24. Rogers K, Zeni MB. Systematic review of medical home models to promote transitions to primary adult health care for adolescents living with autism spectrum disorder. Worldviews Evid Based Nurs. 2015; 12(2):98-107. https://doi.org/10.1111/wvn. 12085.

25. Hand BN, Coury DL, White S, et al. Specialized primary care medical home: a positive impact on continuity of care among autistic adults. Autism. 2020;1362361320953967. https://doi.org/10.1177/ 1362361320953967.

26. Hand BN, Coury DL, Darragh AR, et al. Patient and caregiver experiences at a specialized primary care center for autistic adults. J Comp Effect Res. 2020:cer-2020-0155. https://doi.org/10.2217/cer2020-0155.

27. Benevides TW, Carretta HJ, Graves KY. Case identification and characterization of autistic young adults in 2010 medicare fee-forservice claims. Autism Adulthood. 2019;1(3):210-218. https://doi.org/ 10.1089/aut.2018.0036.

28. Guan H, Li B, Couris CM, et al. Updating and validating the charlson comorbidity index and score for risk adjustment in hospital discharge abstracts using data from 6 countries. Am J Epidemiol. 2011;173(6):676682. https://doi.org/10.1093/aje/kwq433.

29. Centers for Medicare and Medicaid Services. Medicare Preventive Services. Medicare Learning Network Education Tool. Published 2020. https://www.cms.gov/Medicare/Prevention/PrevntionGenInfo/medicare-preventive-services/MPS-QuickReferenceChart-1.html. Accessed April 23, 2020.

30. AAPC. CPT Code - Preventive Medicine Services 99381-99429. AAPC Coder. Published 2020. https://coder.aapc.com/cpt-codes-range/2928 Accessed May 18, 2020.
31. Owens DK, Davidson KW, Krist AH, et al. Screening for HIV infection: us preventive services task force recommendation statement. JAMA. 2019;321(23):2326-2336. https://doi.org/10.1001/jama.2019.6587.

32. Centers for Disease Control and Prevention. 2015-2016 Estimated Influenza Illnesses, Medical Visits, Hospitalizations, and Deaths Averted by Vaccination in the United States. Published December 20, 2019. https: / /www.cdc.gov/flu/about/burden-averted/2015-16.htm. Accessed April 23, 2020.

33. Hand BN, Angell AM, Harris L, Carpenter LA. Prevalence of physical and mental health conditions in Medicare-enrolled, autistic older adults. Autism. 2020;24(3):755-764. https://doi.org/10.1177/ 1362361319890793.

34. UnitedHealthcare. Coverage determination guideline CDG.016.30: Preventive care services. Published online 2020. https://www.uhcprovider. com/content/dam/provider/docs/public/policies/comm-medical-drug/ preventive-care-services.pdf. Accessed April 23, 2020.

35. Cigna. Administrative policy A004: Preventive care services. Published online 2018. https://www.cigna.com/static/www-cigna-com/docs/ health-care-providers/preventative-care-services-a004-administrativepolicy.pdf. Accessed April 23, 2020

36. Centers for Medicare and Medicaid Services. Initial Physical Examination. Published online 2018. https://www.cms.gov/Outreach-and-Education/ Medicare-Learning-Network-MLN/MLNProducts/Downloads/MPS_QRI_ IPPE001a.pdf. Accessed May 21, 2020.

37. Andrews M. Costly confusion: Medicare's wellness visit isn't the same as an annual physical. Kaiser Health News. Published 2019. https://khn. $\mathrm{org} /$ news/medicare-covers-wellness-visit-not-annual-physical/. Accessed May 21, 2020.

38. Ganguli I, Souza J, McWilliams JM, Mehrotra A. Practices caring for the underserved are less likely to adopt Medicare's annual wellness visit. Health Affairs. 2018;37(2):283-291. https://doi.org/10.1377/hlthaff. 2017.1130.

39. Centers for Medicare and Medicaid Services. Nutrition Therapy Services. Medicare.gov. https://www.medicare.gov/coverage/nutrition-therapyservices. Accessed April 23, 2020.

40. CMS Manual System. Pub 100-03 Medicare National Coverage Determinations: Transmittal 137. Published online 2011. https://www.cms.gov/ Regulations-and-Guidance/Guidance/Transmittals /Downloads / R137NCD.pdf. Accessed April 23, 2020.

41. CMS Manual System. Pub 100-03 Medicare National Coverage Determinations: Transmittal 142. Published online 2012. https://www.cms.gov/ Regulations-and-Guidance/Guidance/Transmittals /Downloads / R142NCD.pdf. Accessed April 23, 2020.

42. Aetna. Clinical Policy Bulletin 0049: Nutritional Counseling. Published online 2019. http://www.aetna.com/cpb/medical/data/1_99/0049. html. Accessed April 23, 2020.

43. Nelson A. Unequal treatment: confronting racial and ethnic disparities in health care. J Natl Med Assoc. 2002;94(8):666-668.

44. Naylor KB, Tootoo J, Yakusheva O, Shipman SA, Bynum JPW, Davis MA. Geographic variation in spatial accessibility of U.S. healthcare providers. PLOS ONE. 2019;14(4):e0215016. https://doi.org/10.1371/ journal.pone.0215016.

45. Williams DR, Priest N, Anderson NB. Understanding associations among race, socioeconomic status, and health: patterns and prospects. Health Psychol. 2016;35(4):407-411. https://doi.org/10.1037/ hea0000242.

46. Tay L, Tan K, Diener E, Gonzalez E. Social relations, health behaviors, and health outcomes: a survey and synthesis. Appl Psychol Health WellBeing. 2013;5(1):28-78. https://doi.org/10.1111/aphw. 12000.

47. Kenny L, Hattersley C, Molins B, Buckley C, Povey C, Pellicano E. Which terms should be used to describe autism? Perspectives from the UK autism community. Autism. 2016;20(4):442-462. https://doi.org/10. $1177 / 1362361315588200$.

Publisher's Note: Springer Nature remains neutral with regard to jurisdictional claims in published maps and institutional affiliations. 